other forms of intervention, we would caution against disposing of the day hospital as a means of treatment and assessment especially in dense urban areas as it may present the only opportunity available to carry out detailed multidisciplinary assessments on people before they are relegated to the mercy of 'community care'.

BALL, C.J. (1993) Day care in old age psychiatry. Psychiatric Bulletin, 17, 427-428.

BeATS, B., TRINKLE, D. \& LEVY, R. (1993). Day Hospital provision for the elderly mentally ill within the South East Thames Regional Health Authority. International Journal of Gerlatric Psychiatry. 8, 5, 442-443.

Rolleston. M. \& BALL. C. (1994). Evaluating the effects of brief day hospital closure. International Journal of Geriatric Psychiatry. 9, 51-53.

RAYMOND LEVY and KLAUS BERGMANN, Institute of Psychiatry and Maudsley Hospital, London SE5 8AZ

Sir: I welcome Dr Philpott's contribution to the debate which recognises the validity of the question being asked and the value of taking lessons from the experience of geriatric medicine. Unfortunately, limitations of space led me to curtail this line of enquiry in the original paper. He is right to assert that others may begin to take an increasingly important role in deciding service provision if these questions are not raised.

The main thrust of the discussion in our paper (Rolleston \& Ball, 1994), to which Bergmann \& Levy (this journal) refer, relates to this very issue. The discussion highlights the importance of monitoring decisions regarding services not taken on clinical grounds. The study also says nothing about the relative merits of one form of service delivery over another; only that people miss a service once it has been withdrawn, which comes as no surprise. As some staff from the day hospital were deployed elsewhere in the hospital during this period, perhaps using their skills to support people in their own homes could have reduced the effect we demonstrated.

The local issues which make one form of service delivery more applicable in one area than another may well be paramount. The example of Professor Wilkinson (1994) who has attempted a number of ways of working in the community before settling on a particular model, is a lesson to us all in finding the best way to deliver services to a given population. The answer is unlikely to be the same in all circumstances.

In their initial reply to Ball (1993), Bergmann \& Levy (1994) gave a brief resumé of the types of patients that they had cared for in the day hospital setting, which did not include those suffering from dementia - perhaps because they feel that the citing of their work on dementia and the day hospital is not apposite to the argument. I find this surprising, as such a large percentage of the work done by an old age psychiatry team is with this patient group and their carers. Were none of the 2449 day attendances offered to those with a dementing illness? I agree that it is important to identify the patient groups for whom the day hospital or other service are likely to be most effective, but such a large group of users cannot be summarily dismissed from the debate.

It is the nature of research that results are obtained that do not entirely fit our expectations. These should be used to simulate further discussion and questioning, not to dismiss the researcher as a psychopathological phenomena of dubious diagnostic significance.

BALL. C.J. (1993) The future of day care in old age psychiatry. Psychiatric Bulletin, 17, 427-428.

BERGMANN. K.L. \& LEVY, R. (1994) Day care in old age psychiatry. Psychiatric Bulletin, 18, 53-54.

Rolleston, M. \& BALL, C.J. (1994) Evaluating the effects of brief day hospital closure. International Journal of Geriatric Psychiatry, 9, 51-53.

WILKINSON. D.G. (1994) Day hospitals by any other name. International Journal of Geriatric Psychiatry, 9, 161.

CHRISTOPHER J. BALL, The London Hospital Medical College, Turner Street, London E1 2AD

\section{Social psychiatry}

Sir: I was surprised and dismayed to hear that the College is thinking of changing or dividing the functions and name of the Section of Social, Community and Rehabilitation Psychiatry. This seems unfortunate since social psychiatry is the theoretical base which underpins both rehabilitation and community psychiatry. In rehabilitation, for some reason treatment has often failed and relatively little can be done to alter the person's disabilities. Then the only satisfactory approach in physical rehabilitation is to modify the environment by the provision of ramps, lifts, crutches, guide dogs, wheelchairs and other devices. In psychiatric rehabilitation, changes in the social environment are needed, but this is a much more complicated operation which will become even more difficult as rehabilitation moves out of the mental hospital into the 'community'. It will involve multidisciplinary action in which the psychiatrist has a significantly different, but no less skilful, part to play (informed by an understanding of social psychiatric research findings) if he or she is going to maintain any position of leadership which, I believe, is one of the College's aims.

There is even more at stake; over $\mathbf{4 0}$ years ago Sir Aubrey Lewis wrote that the study of mental illness must be incomplete if social factors were not taken into account and so he founded the MRC Social Psychiatry Unit in the Institute of Psychiatry. Its work and that of the College has still a long way to go: thus the College Section, 
like the Social Psychiatry Unit, needs to be supported and preserved.

Douglas BenNetT, 5 Mill Lane, Iffley, Oxford OX4 4EJ

\section{Section 17 (leave) of the Mental Health Act}

Sir: I have recently run into problems with the use of section 17 (leave) of the Mental Health Act. The local Residential and Nursing Homes Inspection and Registration Unit has indicated that homes which are not registered under the Mental Health Act should not take patients on section 17 leave. There seems to be concern that such patients are "liable to be detained" under the Mental Health Act and therefore should only be in registered homes under the terms of the registration of homes legislation.

It seems that people can be sent to their own home, bed $\&$ breakfast accommodation and hostels but not residential or nursing homes if they are liable to recall to hospital. I have endeavoured to explain that they are only "liable to be detained" if they are recalled to hospital and are of course not detainable in the home.

I wonder if there have been similar experiences in other parts of the country and whether the College could help clarify this issue.

ADAM MOLIVER, Delancey Hospital, Charlton Lane, Cheltenham GL53 9DU

\section{The problem orientated psychiatric discharge summary}

Sir: Psychiatric discharge summaries generally follow a standard format but vary considerably in their content and presentation. We report an investigation into general practitioners' attitudes to a problem orientated psychiatric discharge summary, which includes information shown to be relevant to their needs diagnosis, management, medication, information given to patient, follow-up plans and prognosis (Orrell \& Greenberg, 1986).

A questionnaire accompanied by three versions of a psychiatric discharge summary was sent to 100 GPs in Camden and Islington, London. Summary 1 covered two sides of A4 paper, conformed to the traditional structure and contained detailed information under 11 headings recommended by the Institute of Psychiatry's guidelines. Summary 2 was also on two sides of A4 paper, had a problem orientated list on the front-sheet, and contained brief relevant details under the same headings. Summary 3 was on one side of A4 paper and contained the same problem orientated list as in summary 2 , followed by a single paragraph describing the patient's presentation and management. The questionnaire asked for the summaries to be placed in order of preference and left additional space for comments.

Responses were obtained from 71 of the GPs. Telephone follow-up established that 16 had retired, moved, practised or deceased. The sample size was therefore reduced to 84 and the response rate was $85 \%$. Summary 1 was the first choice of two, second choice of 19 and third choice of 44 . Summary 2 was the first choice of 38, second choice of 20 and third choice of nine. Summary 3 was the first choice of 31 , second choice of 25 and third choice of 11 .

Eight general practitioners included only a first cholce. Sixty-nine out of $71(97 \%)$ preferred the discharge summaries which contained a problem list. Of these $38(54 \%)$ preferred the summary that included the traditional headings and 31 (44\%) preferred the one with a single paragraph outlining presentation and management. Ten general practitioners commented that greater detail would be preferred following an initial admission and the briefer summary for subsequent admissions.

Of a representative sample of inner city GPs, the overwhelming majority therefore preferred the summaries which contained the problem orientated list. Concise and prompt communication with primary care is essential to patient management, and this need has been sharpened by the introduction of contractual arrangements between purchasers and providers. A problem orientated list also allows easier transfer of important information onto computerised records. We believe that the requirements of both psychiatric services and general practitioners can be accommodated by incorporating problem orientated lists into discharge summaries, and suggest that, although it is appropriate to include more detalled information following a first admission, subsequent summaries could be even briefer.

ORRELL. M.W. \& GREENBERG. M. (1986) What makes psychiatric summaries useful to general practitioners? Bulletin of the Royal College of Psychiatrists. 10, 107-109.

SuKHI S. SHERGILl and MAURICE GREenberg, Jules Thorn Day Hospital, St Pancras Hospttal, 4 St Pancras Way, London NW1 OPE

\section{Misuse of the word 'audit'}

Sir: I find your publication informative and stimulating. The articles are concise and wellwritten, and I am pleased to see an increasing number relating to audit. However, as a medical audit officer, it does frustrate me to see the term 'audit' used in the wrong context, particularly in the correspondence columns. 